\section{AKADEMOS}

\section{ISSN: 1995-4743}

Año 13 Vol. 1, n’ $32 \quad$ Enero-Junio 2019

AKADEMOS es una revista semestral. De amplio espacio editorial, para la publicación de trabajos inéditos de investigación, artículos de análisis, reseñas y opinión, en los distintos tópicos de las ciencias, la tecnología, las artes y la cultura.

\title{
Los marxismos después de Marx: El pensamiento crítico de la Escuela de Frankfurt
}

Luis Antonio Tobar

Lic. en Sociología, Facultad Multidisciplinaria de Occidente tobarquinter090@gmail.com

\section{Resumen}

La fundación del instituto de investigaciones sociales en 1922 dio un giro al pensamiento marxista que se venía construyendo. Félix Weil un joven estudiante argentino- alemán junto con otro grupo de intelectuales, entre ellos: Habermas, Adorno, Horkheimer, buscan reinterpretar el marxismo y sacarlo del dogma con que se estaba construyendo en la Unión Soviética. Por ello, deciden abordar una serie de temáticas que giran en torno a la crítica de la irracionalidad de la sociedad capitalista, retomando nuevos ele- mentos de la teoría marxista, poco abordados por Marx y Engels y que eran necesarios para comprender la dinámica de la sociedad de la época. Estas formas de pensamiento se complementan con la visión de dos intelectuales cercanos a la Escuela de Frankfurt, y Habermas. Relacionado a ello, se hizo una comparación con la realidad salvadoreña de algunas tesis sostenidas por dichos pensadores y la desarrollada particularmente por salvadoreños.

Palabras clave: Escuela de Frankfurt, pensamiento crítico, Weil, Adorno, Horkheimer, Marcuse, industrial cultural, racionalidad. 


\section{Abstract}

The foundation of the social research institute in 1922 overturned the Marxist thought that was being constructed. Felix Weil, a German-Argentinian youth and other intellectuals, among them: Habermas, Adorno, and Horkheimer, seek to reinterpret Marxism and take it out of the dogma that was being counstructed in the Soviet Union. As a result, they decide to approach a series of topics around the criticism to the Irrationality of the Capitalist society, retaking new elements of the Marxist theory, which were not approached by Marx and Engels and which were necessary to understand the dynamics of the society of the time. These ways of thinking complement the vision of two intellectuals known to the School of Frankfurt, and Habermas. Based on this, a comparison between the Salvadoran reality in some hypothesis held by some thinkers and the one developed by some Salvadorans particularly has been carried out.

Key words: School of Frankfurt, critical thinking, Weil, Adorno, Horkheimer, Marcuse, industrial cultural, rationality.

\section{Introducción}

El pensamiento crítico de la Escuela de Frankfurt significó un auge en el desarrollo intelectual del marxismo. Los intelectuales que trabajaron unidos bajo la lógica de restaurar un marxismo dogmático puesto en marcha por Stalin, encontraron una oportunidad para realizar distintos trabajos capa- ces de identificar los nuevos dominios del capitalismo, en esa lógica se fundó en 1922 el Instituto de Investigaciones Sociales por Félix Weil.

El presente artículo se propone analizar el aporte de los miembros más destacados, que fueron miembros del Instituto de Investigaciones Sociales y después Escuela de Frankfurt, en lo que concierne a las teorías que desarrollaron, características de su pensamiento, explicación de la realidad de la época y su análisis desde el marxismo para explicar la sociedad capitalista. Tomando en cuenta que muchos de estos intelectuales eran de origen judío y vivieron en carne propia el exilio por la llegada al poder del régimen nazi.

Los aportes de dichos pensadores, son clave para comprender la realidad latinoamericana y salvadoreña, sobre todo porque en la región se instauraron gobiernos de índole autoritaria que promovían el desarrollo de una elite propia del subcontinente. En el país, particularmente los ejercidos por lo que se denominó industrial cultural, fueron puestos en práctica por el General Maximiliano Hernández Martínez, con el apoyo de diversos promotores de la cultura de la época.

Otra de las tesis que se aplican, es la expuesta por Marcuse sobre el dominio de la sociedad capitalista en los individuos, al satisfacerles sus necesidades y promover un Estado de bienestar. Esto sucedió precisamente cuando el FMLN se convirtió en partido político y se sometió al juego del sis- 
tema, donde muchos de sus líderes se convirtieron en una nueva elite.

\section{El origen de la Escuela de Frankfurt}

Los inicios de la escuela se remontan a la fundación del Instituto de Investigaciones Sociales, fundado en 1922 por el argentinoalemán Félix Weil, quien procedía de una familia acomodada de Alemania. Weil había sido influenciado por el único profesor socialista que impartía cátedras de economía en la Universidad de Tubinga, con quien tendría contacto en 1919. Esto lo afirma Wiggershaus (1986), al decir:

Aquí se encontraba entre sus oyentes, en el semestre del verano de 1919, Félix Weil. El estudiante de ciencias sociales y economía de 21 años, proveniente de una familia adinerada que en los días de la Revolución de noviembre se había puesto a disposición del Consejo de Obreros y Soldados de Fráncfort, como su estudiante protegido, había llegado especialmente a Tubinga para escuchar al profesor socialista (...) (pp. 12-13).

Como consecuencia de esta influencia Weil realizaría la primera semana de trabajos marxistas en 1923, en un hotel situado en la ciudad de Turingia apoyado por Karl Korsch. La lógica de llevar a cabo este evento, tenía la intención de la fundación en dicho año del Instituto de Investigaciones Sociales.

Asimismo, los intelectuales que conformaron este instituto tuvieron gran influencia del romanticismo alemán lo cual se reflejó en la mayoría de escritos de los intelectuales, que acompañaron este movimiento. Además, la mayoría era de descendencia judía, por ello, lo mesiánico estará presente en el pensamiento filosófico del Instituto. De igual manera, los intelectuales de este movimiento hicieron duras críticas al marxismo construido en la URSS, como al fascismo de Italia y Alemania, es decir, su pensamiento fue abordado desde la negatividad de la totalidad de estos dos sistemas. Por ello, para Echeverría (2010):

Pues la Escuela de Frankfurt es una escuela que piensa dentro de lo que Lukács llamó, en los años veinte, "la época de la actualidad de la revolución". Y el discurso de la Escuela de Frankfurt es impensable sin la problemática propia de una época, de una larga coyuntura histórica en la que (...) la revolución del mundo moderno capitalista parecía estar a la orden del día (...) (p. 22).

Las décadas de los veinte y treinta en Europa se caracterizó por la llegada de gobiernos fascistas en Italia y Alemania y el arribo de Stalin al poder. En este contexto es donde los intelectuales de la escuela de Fráncfort se desenvuelven. Su pensamiento iba a ser una crítica de esa totalidad negativa a que se había llegado con la construcción de ambos modelos económicos y una crítica a los mismos.

La consolidación de la escuela de Frankfurt sería posible hasta los años treinta con la llegada de Horkheimer, una serie de ensayos marcarían el apogeo intelectual. Tal como, lo plantea Friedman (1986): 
(...) El Instituto de Investigación Social, fundado en Frankfurt. Alemania, en 1923, alcanzó su madurez en 1931 al asumir Max Horkheimer la dirección. Continuó su labor en los Esta- dos Unidos durante el exilio que siguió a la subida de Hitler al poder y del que no retornó a Alemania hasta 1950 (p. 11).

Nueve años después de su fundación, la escuela por fin se consolida y logra formar una base de académicos que para este tiempo ejercen duras críticas al capitalismo, pero también al mismo socialismo que se construye en los países del este europeo. Una de las fuertes críticas es que el proyecto de la clase trabajadora ha fracasado, porque ha construido un estado totalitario en vez de un Estado libre.

De igual manera, se tenía la postura de que ninguno de los sistemas en construcción podía ofrecer algo diferente a la sociedad. El proyecto revolucionario construido en el este, no correspondía con una praxis revolucionario y el capitalismo por el otro había demostrado su fracaso, poniendo al centro la razón como la única lógica que llevaría al progreso de la sociedad. En ese sentido para Echeverría (2010):

(...) la Escuela de Frankfurt maneja un discurso que se va a volver doblemente difícil. Porque va a tener la convicción de que esa conexión tan maravillosamente fácil, supuesta por Lukács entre la conciencia del proletariado y la práctica revolucionaria, es una relación que ya no existe (p.28).
La afirmación anterior muestra lo complejo que era para estos intelectuales entender la construcción de una alternativa al reinante capitalismo industrial, sobre todo porque el socialismo para ellos se había desviado de sus objetivos fundamentales. Stalin junto con sus aliados estaba llevando a la ruina el esfuerzo realizado en 1917 por Lenin. Por otro lado, el capitalismo que se consolido con la ilustración un siglo antes, estaba en crisis y demostraba la incapacidad de satisfacer las necesidades del individuo.

El marxismo soviético para los pensadores de Frankfurt, busca hacer lo mismo que el capitalismo; solo que, bajo otra lógica en la dictadura del proletariado, en el que ya se había dado por muerto al capitalismo y la felicidad se quedaría para siempre. Por ello la crítica que se hacía en palabras de Friedman (1986) era la siguiente:

La base del proyecto frankfurtiano fue la preocupación por el derrumbamiento de lo más valioso de la vida humana. El marxismo, particularmente como se manifestaba bajo Blum y Stalin, no era adecuado para abordar aquella preocupación. El marxismo no pudo entender que su obsesión por la privación de bienes materiales representaba tan exactamente la fetichización de los bienes de consumo como lo hacía la preocupación burguesa por el status. En verdad, la abolición de la escasez crasa en Occidente creó la ilusión de que la relativa igualdad de los hombres en la posesión de los bienes constituía la realización de la condición naturalmente conveniente para los hombres (p. 30). 
Lo anterior no pretende afirmar que el socialismo ha fracasado, sino más bien que la construcción del mismo en las condiciones de la época, se había deformado totalmente de su raíz. Por ello, la conciencia del proletariado y praxis revolucionaria no están en sintonía y el proyecto que ofreció a las masas esperanza en 1917 estaba en juego.

Bajo estas ideas se forjo el pensamiento de la escuela de Frankfurt a lo largo de sus diversas generaciones, en la cual el carácter mesiánico iba a tener una importancia bastante fuerte, así como el distanciamiento del marxismo existente en la Unión Soviética. Del mismo modo la teoría critica sería uno de los aportes más sobresaliente de Horkheimer, para el cual entender el pasado era importante para comprender los fenómenos de la época.

Asimismo, para Benjamín, un pensador que tuvo alguna relación con los intelectuales de esta escuela, el pasado no era algo sin importancia o una suma de hechos históricos. El pasado era la redención de las víctimas, para transformar las condiciones de dominación y lo que llevaría a las masas a cambiar el futuro a través del examen minucioso de la grandeza del pasado de las grandes revoluciones.

\section{El pensamiento crítico de Max Horkheimer}

Horkheimer fue el que retomo la dirección del Instituto de Investigaciones So- ciales en 1931. Su pensamiento central se encuentra en analizar el papel de la teoría crítica en las ciencias sociales y su aplicación a la sociedad de su tiempo. Del mismo modo, estudia la absorción del hombre por el sistema económico en la sociedad industrial avanzada, así como el nuevo papel de la izquierda, tomada de su experiencia en los movimientos sociales en los Estados Unidos.

Para dicho autor, la teoría tradicional ha servido para la consolidación del capitalismo, debido a que es un instrumento que está al servicio de la producción capitalista. Esta teoría es vista como algo natural, a histórico, autónomo e independiente de la ciencia, en ese sentido no es un instrumento al servicio del capitalismo. Por ello, la teoría para Horkheimer (1968) es: (...) "la acumulación del saber en forma tal que este se vuelve utilizable para caracterizar los hechos de la manera más acabada posible" (...) (p. 223).

En relación con lo anterior, para el autor, la racionalidad a que ha llegado el capitalismo parte de que la ciencia está al servicio de una clase, como algo utilitario, que busca un beneficio a través de la utilización del lenguaje. Este lenguaje propio de la sociedad industrial busca legitimar la dominación del hombre sobre otros y el mismo. La siguiente figura ilustra mejor lo dicho anteriormente: 
Figura 1: Teoría crítica de Horkheimer

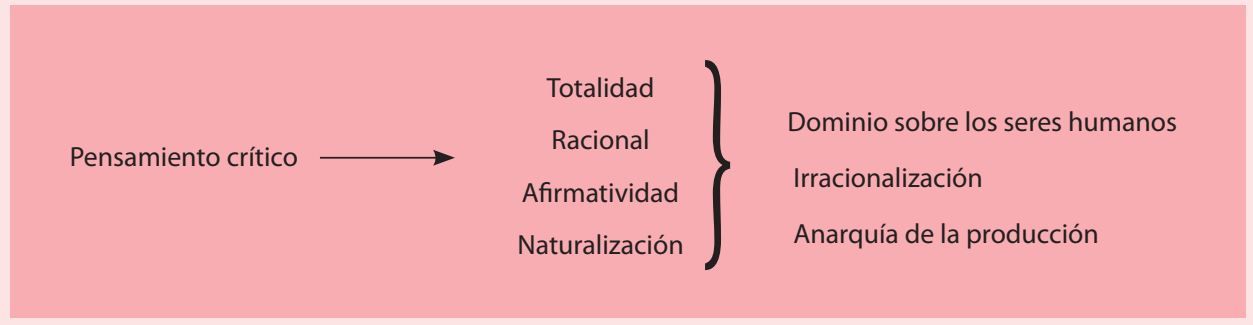

Fuente: elaboración propia

La figura anterior muestra el carácter crítico de la que debe tener la teoría crítica en relación a la teoría tradicional. En ese sentido, esta es un proceso contradictorio que se manifiesta en la lucha contra el dominio. Horkheimer (1968) afirma:

(...) el pensamiento crítico está motivado por el intento de suprimir y superar realmente esa tensión, de suprimir la oposición entre la conciencia de fines, la espontaneidad, y la racionalidad esbozada en el individuo y las relaciones del proceso de trabajo, fundamentales para la sociedad. El pensamiento crítico contiene un concepto del hombre que se opone a sí mismo en cuanto no se produzca esa identidad. (...) (p. 242).

Esta definición muestra la esencia del pensamiento crítico sobre la sociedad industrial avanzada, en el que el hombre era absorbido poco a poco por el sistema. De hecho esa crítica, muestra una oposición entre la naturaleza y la civilización, en tanto, que el hombre la somete a su favor y la pone a sus intereses. Bajo el capitalismo, la felicidad es concebida en base al sufrimiento de los otros, a la felicidad individual de cada hombre sin importarle el resto.

En esa lógica, las victimas el capitalismo ha acumulado desde la ilustración, no puede ser reparada, es decir, ya no se puede cambiar esa realidad que es pasado, pero si se puede construir una economía que satisfaga a ser humano, que busque su autorrealización. Sin embargo, la realidad en la que vivió el autor era muy diferente y se caracterizaba para Horkheimer (1991) por lo siguiente:

En el proceso de su emancipación el hombre participa en el destino del mundo que lo circunda. El dominio sobre la naturaleza incluye el dominio sobre los hombres. Todo sujeto debe tomar parte en el sojuzgarniento de la naturaleza externa - tanto la humana como la no humana 
y, a fin de realizar esto, debe subyugar a la naturaleza dentro de sí mismo. El dominio se internaliza por amor al dominio. Lo que comúnmente se define como meta — la felicidad del individuo, la salud y la riqueza-, debe su significación exclusivamente a su posibilidad de volverse funcional (...) (p. 116).

Bajo esta lógica, el hombre se ve sometido a un dominio de sí mismo para controlar la naturaleza. Dicha transformación lo llevara a su integración funcional al sistema y lo volverá un elemento de utilidad al capitalismo. Mientras la conciencia espontanea no le permita revelarse, este seguirá atado sin poder hacer nada.

La construcción de un sistema diferente, tampoco garantizara para el pensador, la búsqueda de un futuro diferente, donde la naturaleza no envuelva bajo su dominio al hombre, realidad que para la década de 1930 no sucedía, sobre todo, si se toma en cuenta la vulgarización del marxismo en la URSS y el triunfo del fascismo y nacional socialismo en Alemania. Por ese motivo, había que repensar la puesta en práctica de un marxismo al servicio de las mayorías y fundado en un pensamiento crítico.

\section{El pensamiento teológico-fillosófico de Adorno}

Cuando se aborda, el pensamiento de Adorno, no puede verse separado del de Horkheimer, ya que ambos analizan la dominación que ejercía el capitalismo en la época en Alemania. Un concepto fundamental que puede distinguir el pensamiento de los dos autores antes mencionado es el de la Industria Cultural. Adorno en sus primeros años tuvo la influencia de los músicos Berg y Schonberg líderes de la escuela moderna de Viena.

En sus primeros años estudio música, para luego abandonarlos por la filosofía, lo que le permitió desarrollar su pensamiento posterior. Otro de los estudios que realizo, fue el estudio de la personalidad autoritaria en las personas, dicho tema le intereso por el régimen nazi que lo obligo a migrar a otro país, principalmente Estados Unidos. En ese sentido la sociedad para este pensador se hundía en un nuevo género de la barbarie.

Asimismo, tuvo mucha influencia del marxismo y rechazo a la razón como fin último de la modernidad. No compartía que la razón que se había desarrollado desde la ilustración llevaría al máximo desarrollo a una nación, sobre todo porque esta se llegó a convertir en un Dios para el capitalismo. Las ideas de Adorno giraron en torno a dos ideas centrales:

I. Rechaza toda forma de violencia para conseguir el poder.

II. Afirma que hay que analizar el papel de la víctima en la violencia

Las ideas anteriores caracterizan el pensamiento del autor, lo cual le sirvió para desarrollar su sistema filosófico en toda su vida. Por ello, se analizara el concepto de industria cultural vertido en la obra Dialéctica de la Ilustración y sus consecuencias para la sociedad alemana de su tiempo. En un primer 
momento se abordara el concepto de industrial cultural que en palabras de Horkheimer y Adorno (2006) parte de:

(...) La cultura marca hoy todo con un rasgo de semejanza. Cine, radio y revistas constituyen un sistema. Cada sector esta armonizado en sí mismo y todo entre ellos $(\ldots)(\ldots)$ los tersos y colosales palacios que se alzan por todas partes representan la ingeniosa regularidad de los grandes monopolios internacionales a la que ya tendía la desatada iniciativa privada, cuyos monumentos son los sombríos edificios de viviendas y comerciales de las ciudades desoladas (...) (p. 165).

Esta idea planteada muestra como el papel de la cultura tiene un lugar importante en la reproducción de la dominación que ejerce la racionalización en la época. El papel del arte juega un rol estratégico en las estrategias de reproducción del capitalismo. El dominio, no solo tiene que ver con una imposición por la fuerza, sino más bien, por vías alternativas a las tradicionales, entre ellas la música.

El poder que ejerce la industria, cubre todas las esferas de la vida social y los gobiernos han puesto a su servicio este recurso. Por ello para Horkheimer y Adorno (2006):

(...) Hoy, el enigma ha sido descifrado. Incluso si la planificación del mecanismo por parte de aquellos que preparan los datos, por la industria cultural, es impuesta a esta por el peso de una sociedad --- a pesar de toda racionalización--- irracional, esta tendencia fatal es transformada, a su paso por las agencias del negocio industrial, en la astuta intencionalidad de este (...) (p. 169).

Para adorno, el papel que jugaba esa industria que día a día bombardeaba la ideología nacional socialista contaba con diversos medios, que procuraban interiorizar dicha ideología en la población. Este fenómeno, ocurrió de igual forma en El Salvador, durante la dictadura de Maximiliano Martínez con la creación del grupo Masferrer. Dicho grupo difundió a través de la cultura el régimen de Martínez como algo positivo. En ese sentido, para Mejía (2015) dicho grupo:

Entendía, en primer lugar, que no todos somos iguales y, en segundo lugar, que esa desigualdad no es necesariamente mala. Según como el concebía la nación, los cuatro órganos tenían que coadyuvarse y corregirse de manera permanente. Creía que el equilibrio social se rompe si un grupo se aprovecha de otro, si está al servicio de sí mismo en lugar de estarlo al de los demás. A partir de esa idea pudo haber surgido la alianza entre intelectuales, presidencia de la república, terratenientesbanqueros y el obrerismo-campesinado en general dentro de un sistema capitalista donde las cuatro funciones se habían estropeado, por lo que era necesario volver a conciliarlas como parte del esquema minimumvitalista (p.30).

En El Salvador como en Alemania se construían dos gobiernos dictatoriales que buscaban infundir su ideología a través de la cultura. En Alemania se utilizaba, el cine, 
radio y la propaganda publicitaria, En El Salador, la literatura, el folclore y la poesía, fueron los medios adecuados para la idealización de la cultura indígena. Por lo tanto, la industria cultural, era aplicada a los dos contextos en diferentes partes del mundo. La racionalización había encontrado los medios adecuados para imponer una dominación sobre los países, sin que la población diferenciara entre la ficción y la realidad. Por ello, para Horkheimer y Adorno (2006):

El mundo entero es conducido a través del filtro de la industria cultural. La vieja experiencia del espectador de cine, que percibe el exterior, la calle, como continuación del espectáculo que acababa de dejar, porque este último quiere precisamente reproducir fielmente el mundo perceptivo de la vida cotidiana, se ha convertido en el hilo conductor de la producción. Cuanto más completa e integralmente las técnicas cinematográficas dupliquen los objetos empíricos, tanto más fácil se logra hoy la ilusión de creer que el mundo exterior es la simple prolongación del que se conoce en el cine (...) (p. 171).

De esta manera, el cine era un aparato reproductor de la ideología dominante, al igual que la radio y el arte en general. Las formas en que el capitalismo ejercía el dominio, tenía una serie de instrumentos que le sirvieran para legitimarlo. Por otro lado, Adorno estudia la personalidad autoritaria que lleva a los líderes a sustituir los valores democráticos por los violentos, en la instauración de los gobiernos fascistas.
En su libro titulado, la personalidad autoritaria, Adorno y otros intelectuales, se dedican a estudiar la personalidad de los líderes fascistas y que factores socio- psicológicos influyen en dichas conductas. Para los autores es importante comprender, como surgen los líderes autoritarios y que características influyen de gran medida en los individuos. En el prefacio del libro mencionado Adorno, Frenkel, Levinson y Nevitt (1965) establecen el objetivo de dicha investigación al decir:

(...) Buscamos desarrollar y promover una comprensión de los factores sociopsicológicos que hacen posible que el tipo de hombre autoritario amenace reemplazar al tipo individualista y democrático que ha prevalecido en el último siglo y medio de nuestra civilización, así como una comprensión de los factores mediante los que se puede contener esta amenaza (...) (p. 166).

Este elemento explica el origen de la construcción de los gobiernos fascistas de la época. Esto implica, estudiar la personalidad de los individuos, los cuales llegan al poder y controlan las sociedades, de tal modo que ejercen un dominio total sobre los demás. Dichos gobiernos llegan a establecer imágenes de salvación en la población, en los cuales se crea una imagen divina de los líderes. Por ello, para Adorno et al (1965):

(...) De acuerdo con esta teoría [personalidad], los efectos de las fuerzas ambientales en el moldeamiento de la personalidad son en general tanto más profundos cuan- 
to más temprano aparecen en la historia vital del individuo. Las influencias más importantes sobre el desarrollo de la personalidad se presentan educación del niño dentro del círculo familiar (...) (p. 173).

La investigación de este fenómeno, permitió estudiar a los líderes autoritarios fascistas y como en estos se forman las personalidades autoritarias. De esa manera se estudian diversos factores, entre los cuales se encuentran: socio-psicológicos, económicos, políticos y el carácter de las instituciones que permiten desarrollar este tipo de personalidad. Por ende, para Adorno se había llegado a un nuevo género de la barbarie.

\section{La visión crítica de Herbert Marcuse}

En relación con los intelectuales anteriores, Marcuse fue más allá de entender el dominio del capitalismo y se atrevió a predecir el papel del hombre crítico en la sociedad industrial y la nueva tarea de los partidos de izquierda o los movimientos de liberación. Su contacto con diversos movimientos sociales, le permitió mejorar la visión de las tareas de la izquierda en el mundo.

A partir de lo anterior, formulo un nuevo concepto de socialismo, tomando en cuenta dos condiciones principales:

I. Las nuevas formas de dominación en la sociedad capitalista avanzada (Estado de bienestar).

II. Satisfacción de las necesidades (especialmente consumo).
De igual manera, Marcuse (1973) haciendo una crítica a esta sociedad donde el hombre está inmerso y yendo más allá de lo normal en cuanto a la dominación, establece:

El análisis está centrado en la sociedad industrial avanzada, en la que el aparato técnico de producción y distribución (con un sector cada vez mayor de automatización) funciona no como la suma total de meros instrumentos que pueden ser aislados de sus efectos sociales y políticos, sino más bien como un sistema que determina a priori el producto del aparato tanto como las operaciones realizadas para servirlo y extenderlo. En esta sociedad el aparato productivo tiende a hacerse totalitario en el grado en que determina no solo las ocupaciones, aptitudes y actitudes socialmente necesarias, sino también las necesidades y aspiraciones individuales (...) (p. 17).

Bajo esta lógica, el dominio total del capitalismo industrial, interviene e las necesidades del hombre y lo condiciona, en el sentido que trata de absorberlo en base al bienestar y el consumo. Para el autor, la sociedad industrial, se manifiesta de la siguiente manera, necesidad/libertad y biológico/artificial. En esta dirección, la clase trabajadora en una clase revolucionaria "en sí" pero no "para sî" en la que se confunde los intereses de los explotados con la de los explotadores. Por ello, Marcuse (1973) afirma:

(...) Una sociedad que parece cada día más capaz de satisfacer las necesidades de los individuos por medio de la forma en que está organizada, priva a la indepen- 
dencia de pensamiento, a la autonomía y el derecho de oposición política de su función critica básica. Tal sociedad puede exigir justamente la aceptación de sus principios e instituciones, y reducir la oposición a la mera promoción y debate de políticas alternativas dentro del statu quo (...) (pp. 23-24).

De esta manera, se ilustra el papel del aparato productivo en la sociedad industrial avanzada y como el pensamiento del hombre crítico es absorbido cada vez más por el sistema. Esta lógica, se ejemplifico después de los acuerdos de Paz en El Salvador, cuando el FMLN entraba a la lógica del sistema partidario y se establecía una contradicción entre la visión de cómo transformar la realidad de esta óptica. Para Hándal (2014):

(...) Se hace lo que la correlación de fuerzas permite, pero sin perder el rumbo para llegar a la trasformación revolucionaria, a la reestructuración del sistema. La vida ha demostrado que no son compatibles; lo imperdonable es la renuncia a la lucha por el poder, llegar al gobierno y no hacer un poder revolucionario (p. 6).

Desde ese punto de vista, para el FMLN entrar en la vida política, era algo nuevo y transformar la sociedad implicada renunciar a los jugosos premios que el sistema capitalista ponía en bandeja de plata a los nuevos funcionarios. En palabras de Marcuse, el debate de la oposición seria algo que no mostraría oposición en grandes rasgos. Los distintos funcionarios, fueron absorbidos por el sistema capitalista antes de la llegada al poder del FMLN. Por lo tanto, Marcuse (1973) afirma:

(...) En virtud de la manera en que ha organizado su base tecnológica, la sociedad industrial contemporánea tiende a ser totalitaria. Porque totalitaria no solo es una coordinación política terrorista de la sociedad, sino también una coordinación técnico-económica no terrorista que opera a través de la manipulación de las necesidades por intereses creados, impidiendo por lo tanto el surgimiento de una oposición efectiva contra el todo (...) (p. 25).

En el pensamiento revolucionario de Hándal, las nuevas formas de dominación del capitalismo no habían sido comprendidas. La creación de necesidades y asegurar la satisfacción de estas en los funcionarios opositores, tuvo éxito en el mediano plazo después de la muerte del mismo. Ante esta lógica, que proponía Marcuse para cambiar la realidad que estaba afectando ese pensamiento crítico y conciencia de clase en los trabajadores.

En esa misma lógica, partía de la conformación de nuevos sujetos de la revolución, de tal manera, que ya no habría un único sujeto capaz de transformar la realidad, sino una pluralidad de actores sociales con un pensamiento heterodoxo, liberándose del marxismo tradicional. Tomando en cuenta, que la evolución del capitalismo es diferente de la que mostraba a principios del siglo pasado, con la de la época de Marcuse y Hándal.

Por ende, la crítica que debía plantearse, tendría que girar en torno a la lógica de la felici- 
dad que la sociedad industrial planteaba en cuanto a la puesta en marcha del Estado de bienestar, que presentaba la siguiente característica para Marcuse (1968) al decir: (...) "las relaciones de la producción capitalista son responsables no solo de la servidumbre y el esfuerzo sino también garantizan la mayor felicidad y diversión accesibles a la mayoría de la población y en consecuencia distribuyen más bienes que antes” (p. 21).

Para Marcuse, un tema central de la dominación capitalista era el éxito, bajo esta perspectiva la sociedad industrial al lograr satisfacer e integrar al sujeto al sistema, mostraba su eficacia. El triunfo de la razón era visto como algo inalcanzable en otro tiempo, por lo tanto, habría que plantearse en estas condiciones, la nueva tarea de la izquierda. Por ello debía nutrirse de dos formas de lucha clave:

I. En primer lugar, de los movimientos artísticos que juegan un papel fundamental en la concientización.

II. De los movimientos feministas que planteaban la construcción de un socialismo feminista.

Lograr estas tareas era uno de los desafíos que se le presentaba a la izquierda, para el autor mencionado, mientras más se nutriera de diversas corrientes y formas de lucha, las transformaciones podían plantearse de una manera más amplia. Como afirmaba Marcuse, ningún partido político podía trasformar la realidad por medio del parlamentarismo. La poca credibilidad que había llegado a tener los partidos, es un claro reflejo de la opi- nión mencionada. En ese sentido, la tarea de la nueva izquierda para Marcuse (1969) es la siguiente:

(...) Creo que hoy la Nueva Izquierda es la única esperanza que tenemos. Su tarea --- prepararse y preparar a los demás, no esperar, prepararse hoy, ayer y mañana, en pensamiento y en acción, moral y políticamente, para el momento en que se disuelva la cohesión represiva del capitalismo corporativo y se abra un espacio donde pueda comenzar la tarea real del socialismo libertario (...) (pp. 96-97).

De esa manera, el trabajo que deben realizar los partidos, desde finales de los años 60 , tenía que ver con replantearse la construcción del socialismo en los diferentes países donde estaba asentado. Esta crítica es una de las tareas de las izquierdas en América Latina, donde los errores cometidos en el pasado son un desafío para construir nuevos proyectos, dejando de lado los viejos dogmatismos y el centralismo revolucionario que no permitió la construcción de un socialismo de acuerdo a las propias condiciones en cada región.

\section{El pensamiento de Ernst Bloch}

Para comprender el pensamiento de Bloch, se debe tomar en cuenta el contexto en que desarrolló su pensamiento. Los principales acontecimientos mundiales que influyeron en dicho pensamiento fueron: las dos guerras mundiales, la revolución bolchevique y la guerra fría. Este último suceso marcaría un cambio radical en las ideas del autor so- 
bre el marxismo que se pretendía construir en la URSS.

En el transcurso del tiempo, sus ideas giran en torno a poner en discusión la esperanza que la humanidad en cierta medida ha perdido, pero que, al estudiar distintos postulados del marxismo, no desarrollados por la revolución bolchevique, pretenden ofrecer que un mundo mejor es posible. Algunos de dichos análisis llevarían a que el pensador, fuera exiliado de la República Democrática Alemana en 1961.

En relación a lo anterior, uno de los principales conceptos que Bloch retoma de las principales revoluciones, es el de la utopía social, con ello explica que dichos sucesos han dejado diferentes aportes a la humanidad, lo cual puede ser retomado en la construcción de un socialismo, donde el mundo no está clausurado, sino más bien abierto a nuevas necesidades. Por ello, en el principio esperanza una de sus más importantes obras, se analizan una serie de utopías, que para el autor contienen aportes importantes para el marxismo del siglo XX.

Con lo anterior, dicho pensador, parte analizando el concepto de los sueños desarrollado por Freud, al cual supera partiendo del concepto de sueños diurnos, con el cual el hombre puede soñar su realidad despierto, sin perder su ya no consciente. Por ello, Bloch (2006) afirma:

(...) Porque lo normal, habría que pensar, es, o debería ser, que millones de hombres no se dejen dominar, explotar y des- heredar al largo de milenios por una clase superior. Porque lo normal es que una mayoría tan abrumadora no permita que sean ellos los abominados de la tierra. Lo verdaderamente desacostumbrado, lo extraño en la historia es el despertar de esta mayoría (...). (...) E incluso donde las revoluciones triunfaron, lo que muestran es más el cambio de los opresores que su eliminación. El fin de la miseria: durante un tiempo increíblemente largo esta divisa no ha sido algo normal, sino una fábula, y solo como un sueño soñado despierto ha sido temida en cuenta (p. 35).

La afirmación anterior, para Bloch parte del supuesto de que las utopías soñadas por el hombre solo existen en esos sueños de noche de los hombres y que la verdadera transformación no ha ocurrido, porque no se ha soñado despierto, tomando en cuenta lo aun no acontecido en esas utopías, es decir, las posibilidades desde los sueños diurnos colectivos. Bajo esa lógica, la historia para el autor empieza al final, porque de todo lo sucedido en las revoluciones a lo largo de la historia, pueden rescatarse elementos positivos en las mismas, que lleven a la emancipación de los sujetos.

En ese sentido, el marxismo no debe de tomarse como algo ya acabado, un mundo donde todo está superado y realizado. La historia es un proceso dialecto que se heredó del pensamiento de Hegel. Por lo tanto, "En Hegel hay algo que lleva más allá de Hegel: su filosofía es un suelo en el que puede florecer una rosa mucho más bella, mucho más misteriosa, mucho más lumino- 
sa que la que florece en la cruz del Estado". (L. Monterrosa, comunicación personal, 26 de septiembre de 2017).

Esto demuestra ese proceso dialectico en la construcción de la historia, que para Bloch se debe retomar del pensamiento hegeliano. De ese modo, en esas utopías debemos recuperar, el sedimento utópico que estas aportaron en su momento y que en la actualidad puede ayudarnos en la transformación de la realidad y que se reflejaran en la esperanza de la humanidad. Pese que, para el autor, todavía no se ha llegado a esa sociedad por la que el ser humano ha soñado, tampoco se ha fracasado del todo, lo cual expresa de la siguiente manera:

El proceso del mundo aún no se ha alcanzado en ninguna parte, pero también es cierto que aún no se ha frustrado en ninguna parte, y los hombres pueden ser, en la tierra, los guardagujas de su camino todavía no decidido en cuanto a su salvación, pero tampoco en cuanto a su condenación (L. Monterrosa, comunicación personal, 26 de septiembre de 2017)

De esta manera, no todo está perdido, pese a los fracasos de ciertos procesos revolucionarios que han terminado en derrotas para los trabajadores. Por el contrario, se debe construir un marxismo cálido, que permita construir con esos sueños diurnos sobre la realidad. Por lo tanto, para Bloch (2007): (...) El paso erguido es primeramente solo un deseo, el deseo de vivir sin explotación y sin señor. Aquí, sobre todo, el sueño diurno flota tan duradera como necesariamente sobre lo llegado a ser, sobre lo no logrado, arrastrándolo consigo (...) (p. 500).

Lo anterior, implicaba ver el mundo en una construcción de un futuro mejor, donde la esperanza, era el camino a alcanzar, es decir, una conciencia utópica, lo que no ha ocurrido en el mundo. Esto se alcanzaría mediante los sueños diurnos retomados de Freud, pero modificado por el autor. Por ello, Bloch (2007) afirma:

El mañana vive en el hoy; siempre se pregunta por él. Los rostros se han vuelto en la dirección utópica han sido desde luego, distintos en cada época, como muy distinto ha sido también lo que en detalle y de caso en caso pensaban ver allí. La dirección, en cambio, es afín por doquiera, más aún, la misma en su objetivo encubierto; es una dirección que se nos aparece como lo único inmutable en la historia (...) (p. 509).

Esta afirmación, hecha en el principio Esperanza, Tomo III, sigue bajo la lógica que en la historia se ha pensado en las utopías como una fantasía, una fábula, sin aterrizar en los verdaderos cambios que favorezcan a las mayorías. Esos sueños siempre han sido nocturnos y se le ha hecho creer a la humanidad, como utopías que pueden ser pensadas en los sueños nada más.

Otro de los aspectos estudiados por Bloch, tiene que ver con el interés por los herejes en historia. Uno de ellos se refleja en el estudio de Thomas Munzer: teólogo de la revolución, el cual significa para el autor lo 
dialectico que la historia tiene que recuperar. En ese sentido, Bloch (1968), describe a Munzer de la siguiente manera:

(...) Y sin embargo, en el caso de este teólogo activo de la revolución justamente, lo uno y lo otro, la acción y la lejana meta, lo ideológico y la idea puramente religiosa, están tan correccionalmente entre lazados, que sobre todo en los ímpetus de la juventud, la desbordante y resplandeciente conciencia de su misión en la tierra con la cual se presenta entre los últimos taboristas el odio a los señores, el odio a los clérigos, la reforma eclesiástica y el éxtasis mesianista, se intercambian los conceptos casi sin transición (...) (p.23).

La vida de Munzer, explicaba eso no común de la historia, esa representación dialéctica de la historia y de ponerse de lado de las mayorías. Dicho teólogo representaba una herejía para la iglesia de su tiempo, pero para Bloch era lo que todo líder de la iglesia debería hacer y mostrar en esa lógica, la esperanza, esos sueños diurnos, en el que el mañana sería un porvenir mejor.

Por ello, la esperanza significa para Bloch: "la más humana de todas las emociones; al mismo tiempo, está referida al horizonte más amplio y más luminoso" (L. Monterrosa, comunicación personal, 26 de septiembre). Eso mismo, inspiro Munzer para los campesinos y obreros que buscaban un mejor futuro lejos de la explotación y la esclavitud, por la cual no se debe dejar de luchar por una utopía alcanzable.

\section{Más allá de la Escuela de Frankfurt: la filosofía de Jurgen Habermas}

Para finalizar se abordará el pensamiento de Habermas, particularmente su obra Ciencia y Técnica como Ideología. En esta obra el autor, ejercerá una dura crítica a los métodos utilizados por el capitalismo para alcanzar la máxima producción. La técnica como herramienta de la ciencia, reproduce la ideología capitalista por medio de la tecnología, es decir, mediante los procesos de racionalización. En esa lógica Habermas (1986):

(...) En su crítica a Max Weber, Marcuse llega a la siguiente conclusión: El concepto de razón técnica es quizá él mismo ideología. No sólo su aplicación, sino que ya la técnica misma es dominio sobre la naturaleza y sobre los hombres: un dominio metódico, científico, calculado y calculante. No es que determinados fines e intereses de dominio sólo se advengan a la técnica a posteriori y desde fuera, sino que entran ya en la construcción del mismo aparato técnico (...) (p. 55).

Por ello, la técnica no solo es un instrumento de la ciencia, es una forma de hacer ideología, basada en métodos racionales. El intelectual alemán retoma algunos conceptos de Weber, pero los utiliza en contra de la lógica del dominio de la razón capitalista. La racionalidad que presentaba una forma de progreso en las sociedades avanzadas, no mostraba ese carácter de dominio económico, político y social que están dentro del mismo. Por lo tanto, Habermas descu- 
bre esas formas de dominación que se van a concretar en la ideología.

En el desarrollo del capitalismo, la reproducción del mismo, ocurre de diversas maneras y de esta manera reproduce su ideología. La ciencia y técnica se encuentran dentro de esos instrumentos que constantemente están cumpliendo dicha función, bajo métodos racionales, particularmente la tecnología, que juegan un dominio económico y político sobre la sociedad. De hecho, los teóricos de la Escuela de Frankfurt harían duras críticas a este sistema heredado desde la ilustración y el cual se ha convertido en un mito, parecido a la fe de los cristianos, que mantiene en pie al capitalismo. Por ende, para Habermas (1986):

(...) El operacionalismo teórico vino al cabo a corresponderse con el práctico. El método científico, que conducía a una dominación cada vez más eficiente de la naturaleza, proporcionó después también tanto los conceptos puros como los instrumentos para una dominación cada vez más efectiva del hombre sobre el hombre a través de la dominación de la naturaleza (...) (p. 58).

Lo anterior demuestra, que la ilustración trajo consigo la transformación de la naturaleza, pero también el dominio del mismo hombre por el hombre. Este se vuelve un esclavo de la producción y la técnica como forma de dominación ideológica en el desarrollo del capitalismo. Por medio de la creación de diversas mercancías y de la esclavización del hombre, la tecnología promueve el enriquecimiento de una capa social a costa de otra.

De igual manera, para Habermas el desarrollo de la tecnología, provoca la absorción del hombre al sistema, en la que el factor de la producción lo hace sentir parte de este, ejerciendo un dominio económico y político que permite seguir reproduciendo la lógica de la racionalización. La burocracia juega un papel importante en la incorporación de mano de obra al trabajo asalariado, ya que establece una institucionalización capaz de mantener bajo su dominio a una cantidad grande de personas.

Por otro lado, para Habermas (1986) la técnica define lo global en la producción material, lo que incluye la producción de la cultura, por esto, proyecta una totalidad histórica a lo largo del tiempo. Su dominación es tan eficaz que no deja ningún espacio en donde esté presente la racionalización. Además, dicho autor retoma el concepto de acción comunicativa el cual sirve como un instrumento para mejorar la adaptación de las personas al sistema capitalista.

Bajo este dominio racional, la ciencia juega un papel importante en la acción racional, que conlleva a ejercer una mayor dominación. Por ello, Habermas (1986):

Desde el último cuarto del siglo XIX se hacen notar en los países capitalistas avanzados dos tendencias evolutivas: 1) un incremento de la actividad intervencionista del Estado, tendente a asegurar la estabilidad del sistema, y 2) una creciente interdependencia de investigación y técni- 
ca, que convierte a las ciencias en la primera fuerza productiva (...) (p. 81).

Esta realidad planteada, muestra como la consolidación de las ciencias experimentales, fueron auxiliares para que el capitalismo mejorara la producción y con ello la tecnología. Desde mediados del siglo XVIII hasta principios del XX, la ciencia tuvo un desarrollo, jamás visto antes. Ello conlleva a un desarrollo de la tecnificación de la producción capitalista y las mercancías se producen en miles cada segundo.

En esa lógica, el capitalismo ofrece todo tipo de satisfacción para las personas, inculcando su dominio no por medio de la coerción, sino a través de otros medios, por ende, Habermas (1986) lo define así:

El capitalismo viene definido por una forma de producción que no sólo plantea, sino que también resuelve este problema. Ofrece una legitimación del dominio, que ya no es menester hacer bajar del cielo de la tradición cultural, sino que puede ser buscada en la base que representa el trabajo social mismo (...) (p. 76).

Esto demuestra que las nuevas formas de dominación que ha alcanzado el capitalismo en aquellas sociedades altamente desarrolladas, en la que los individuos se hacen parte del sistema y son absorbidos por el trabajo social, que les ha planteado la satisfacción de sus necesidades y la mejora, lo cual garantice un bienestar para los mismos. Por lo tanto, ciencia y técnica son dos mecanismos ideológicos de dominación que se expanden a toda la sociedad, ofreciendo felicidad y bienestar.

\section{Conclusiones}

El Instituto sobre Investigaciones Sociales fue el nombre con que inició la actividad intelectual de la Escuela de Frankfurt en 1922, la cual tuvo como fundador a Félix Weil quien compartía las ideas marxistas escuchadas en las cátedras, ofrecidas por algunos socialistas de la época.

Una de los movimientos literarios que influyó en el pensamiento de la Escuela de Frankfurt fue el romanticismo alemán, quien dio elementos críticos olvidados por las teorías de índole progresista y que fue adaptado a la crítica contra el capitalismo industrial avanzado de los años 30.

El pensamiento que caracterizó a la mencionada escuela, fue una crítica al marxismo dogmático construido en los países del este europeo. Por ello, se buscaba refrescar el marxismo desde una óptica intelectual, que fuera capaz de atacar el avance del capitalismo desde diversas corrientes olvidadas en los autores marxistas clásicos.

El principal aporte de Horkheimer fue distinguir entre la teoría tradicional y la teoría crítica que buscaba ir más allá del simple significado y acumulación de conocimientos. La diferencia entre ambas teorías radica en que la tradicional está al servicio de las clases dominantes, mientras que la crítica dotaba a los individuos de una conciencia sobre su situación en la sociedad. 
Para Adorno y Horkheimer parten de un dominio ejercido por el capitalismo a través de los que ellos denominaron la industria cultural. Bajo esa lógica, la expansión del capitalismo industrial se ejerce mediante diversos medios, tales como la radio y el cine. Además, particularmente adorno está en contra de cualquier uso de la violencia para llegar al poder, asimismo, crítica la lógica del marxismo soviético, visto como una imagen divina.

El principal aporte de Marcuse fue el de identificar como el hombre es absorbido por el sistema capitalista, mediante la satisfacción de sus necesidades. Por ello, el capitalismo ha mutado hacia nuevas formas de dominación que antes no existían. Por otro lado, propone la construcción de una nueva izquierda, el cual debe fortalecerse con los diferentes movimientos de liberación, alejados de la burocracia estatal, de los dogmatismos reinantes en la época y sobretodo donde la autocrítica juegue un papel importante.

El pensamiento de Bloch, se caracteriza por el concepto de esperanza, bajo el cual y pese a las condiciones adversas de la construcción del socialismo como forma utópica está en crisis, todavía hay horizontes utópicos posibles en los cuales la humanidad deposite su confianza. Por lo tanto, debemos soñar despiertos sobre la base de la realidad, donde nada esta ganado, ni nada está perdido tampoco.
Para la realidad salvadoreña el dominio que se ejercía desde una elite oligárquica, no fue tan diferente a la sucedida en Europa. La industrial cultural también fue puesta en práctica por Martínez después de la masacre de 1932, por medio de algunos promotores de la cultura de la época. De igual manera, después de los acuerdos de paz, el hombre fue absorbido por el sistema capitalista y la tesis de entrar al sistema para cambiarlo de Schafick no funciono, ya que al cabo de unos años cayeron en el juego del capitalismo.

Para Habermas, el sistema capitalista establece formas de dominación más allá de establecer su ideología y es capaz de que los individuos la acepten y la reproduzcan a través de la ciencia y la tecnología, que son dos técnicas que utiliza como formas invisibles de la dominación. Por lo tanto, el conocimiento juega un papel importante que el capitalismo utiliza a su favor para dominar tranquilamente a toda una sociedad.

De manera general, la teoría crítica de la escuela de Frankfurt se caracterizó por ir en contra de la concepción dogmática en la que se había sumergido el marxismo de la época. Por ello, se buscaba construir una realidad diferente y sobre un marxismo más cálido, capaz de representar las diferentes situaciones y su posible transformación que seguía siendo un horizonte utópico, pese a la coexistencia con el marxismo soviético. 


\section{Referencias bibliográficas}

Adorno et al (1965). La personalidad autoritaria. Buenos Aires: Editorial Proyección.

Bloch, E. (2006). El principio esperanza (Tomo II). Madrid: Trotta.

Bloch, E. (2007). El principio esperanza (Tomo III). Madrid: Trotta.

Bloch, E. (1968). Thomas Munzer. Teólogo de la revolución. Madrid: Editorial Ciencia Nueva.

Echeverría, B. (2010). Una introducción a la Escuela de Frankfurt. Contrahistoria (15), pp. 19-50

Friedman, G. (1986). La filosofía política de la escuela de Frankfurt. México: Fondo de Cultura Económica.

Hándal, S. (2014). Legado de un revolucionario. Del FMLN tras los Acuerdos de Paz al FMLN que hoy necesitamos. San Salvador, El Salvador: Ocean Sur.

Habermas, J. (1986). Ciencia y técnica como ideología. Madrid: Tecnos.
Horkheimer, M. (1991). Critica de la razón instrumental. Madrid: Editorial Trotta.

Horkheimer, M. (1968). Teoría critica. Buenos Aires: Amorrortu.

Horkheimer, M. y Adorno, T. (2006). Dialéctica de la ilustración. Madrid: Editorial Trotta.

Marcuse, H. (1973). El hombre unidimensional. Ensayo sobre la ideología de la sociedad industrial avanzada. México: Editorial Joaquín Mortiz.

Marcuse, H. (1968). Un ensayo sobre la liberación. México D.F.: Editorial Joaquín Mortiz.

Marcuse, H. (1969). La Sociedad Carnívora. Buenos Aires: Editorial Galerna.

Mejía, O. (2015). Aliados con Martínez. El papel de los intelectuales tras la matanza de 1932. San Salvador, El Salvador: UCA Editores.

Wiggershaus, R. (1986). La escuela de Fráncfort. México: Titivillus. 
